\title{
Accuracy of intraoral scan images in full arch with orthodontic brackets: a retrospective in vivo study
}

\author{
Young-Kyun Kim ${ }^{1,2} \cdot$ So-Hyun Kim ${ }^{3} \cdot$ Tae-Hyun $\mathrm{Choi}^{3} \cdot$ Edwin H. Yen ${ }^{4} \cdot$ Bingshuang Zou ${ }^{4} \cdot$ Yonsoo Shin $^{3}$. \\ Nam-Ki Lee ${ }^{3}$ (D)
}

Received: 15 May 2020 / Accepted: 8 January 2021 / Published online: 21 January 2021

(C) The Author(s) 2021

\begin{abstract}
Objectives The purpose of this retrospective study was to evaluate the accuracy of intraoral scan (IOS) images in the maxillary and mandibular arches with orthodontic brackets.

Material and methods From digital impressions of 140 patients who underwent orthodontic treatment, consecutive IOS images were selected based on standardized inclusion criteria: Two pre-orthodontic IOS images (IOS1 and IOS2) of permanent dentition with fully erupted second molars and IOS images obtained immediately after orthodontic bracket bonding (IOSb). Superimpositions were performed to evaluate the reproducibility of repeated IOS images. Accuracy of IOSb images was analyzed by comparing the average surface errors between IOS1c and IOS2c images, which were IOS images cut based on the same region of the interest as between IOS1 and IOSb images.

Results A total of 84 IOS images was analyzed. The average surface errors between IOS1 and IOS2 images were $57 \pm 8 \mu \mathrm{m}$ and $59 \pm 14 \mu \mathrm{m}$ in the maxillary and mandibular arch, respectively, and their reliability was almost perfect. The average errors between IOSb and IOS1c images exhibited an increase, which measured $97 \pm 28 \mu \mathrm{m}$ in the maxillary arch and $95 \pm 29 \mu \mathrm{m}$ in the mandibular arch. These surface deviations between IOSb and IOS1c images were significantly larger in each region as well as entire dentition $(P<0.001)$ compared to those between IOS1c and IOS2c images.

Conclusions The average surface errors of the scans with brackets showed increased values compared with those without brackets. This suggests that orthodontic brackets could affect the trueness of intraoral scan images.

Clinical relevance It is necessary for clinicians to consider the effect of brackets on digital impression when using IOS images in orthodontic patients.
\end{abstract}

Keywords Accuracy $\cdot$ Intraoral scan images $\cdot$ Orthodontic brackets $\cdot$ Digital impression

\section{Introduction}

Digital technologies have been applied to obtain digital models, calculate spacing and crowding, simulate virtual tooth

Nam-Ki Lee

ortho0328@naver.com

1 Department of Oral and Maxillofacial Surgery, Seoul National University Bundang Hospital, Seongnam, South Korea

2 Department of Dentistry \& Dental Research Institute, School of Dentistry, Seoul National University, Seoul, South Korea

3 Department of Orthodontics, Seoul National University Bundang Hospital, Seongnam, South Korea

4 Department of Orthodontics, Faculty of Dentistry, University of British Columbia, Vancouver, British Columbia, Canada movements, virtualize orthognathic surgery, and fabricate surgical wafers [1-3]. Measurements on 3-dimensional (3D) dental models, which were rendered from either CBCT or extraorally digitized plaster casts, were clinically reliable and accurate compared to those from current gold standard plaster models $[4,5]$. Furthermore, 3D printing of some orthodontic appliances has been introduced [6,7].

Intraoral scanning is efficient, less stressful, and exhibits good acceptability [8-12], which allows clinicians to obtain patients' occlusion digitally without taking conventional impressions. Recently, some studies reported that the accuracy and reproducibility of intraoral scan images varies depending on different types of scanners [13-15]. Jeong et al. demonstrated a precision range from $58 \mu \mathrm{m}$ to $116 \mu \mathrm{m}$ with two types of intraoral scanners [16]. Kim et al. found that, during scanning complete-arch models with different cavity preparations, the Trios scanner 
showed the highest precision $(34.7 \mu \mathrm{m})$, and the E4D scanner the lowest precision $(357.1 \mu \mathrm{m})$ [17]. However, most of the studies were performed by scanning plaster or custom reference models, not directly from intraoral conditions of patients $[13,18,19]$.

It is challenging to obtain accurate intraoral scan (IOS) images of full arches with various fixed orthodontic appliances, under intraoral environments with saliva, restorations, debridement, tongue, and cheeks. Considering these clinical conditions, further studies on intraoral scanning are needed. To the authors' knowledge, there have been few studies on the accuracy of intraoral digital impressions of full arches with orthodontic appliances. Prior to such studies, we evaluated the reproducibility of IOS images acquired in maxillary and mandibular arches as baseline and then the accuracy of those with brackets. In particular, this study tested the hypothesis that among digital impressions, the accuracy of IOS images from dentitions with bonded brackets would not differ from those without brackets. The specific purpose of this study was to evaluate the trueness of IOS images with orthodontic brackets in the maxillary and mandibular arches.

\section{Material and methods}

This retrospective study was reviewed and approved by the Institutional Review Board of Seoul National University Bundang Hospital (B-1911/574-105). Digital impressions were collected from 140 patients who underwent pre-orthodontic treatment records from January 2017 to January 2020 at Seoul National University Bundang Hospital. The IOS images were selected by the following inclusion criteria: (1) permanent dentition with fully erupted second molars, (2) no missing teeth, (3) no metal crowns, and (4) intraoral scan data within 1 month, before and immediately after the orthodontic bracket bonding. The IOS images with crowding greater than $5 \mathrm{~mm}$ were excluded (Fig. 1).

\section{Image acquisition}

All IOS images were obtained by an experienced orthodontist (SH. K), who was specially trained and had performed dozens of practice scans, using an intraoral scanner (Carestream CS $3600 \AA$, Carestream Dental, Atlanta, GA) according to the manufacturer's instructions. The scanning procedure was performed for each patient in the dental chair in an upright position $[8,11]$. The pre-orthodontic digital impressions acquired twice with an interval of 2 weeks were regarded as the first and second IOS images (IOS1 and IOS2, respectively). Digital impressions obtained immediately after bracket bonding without archwire insertion were defined as IOS images with orthodontic brackets (IOSb). Each IOS dataset was exported as Standard Tessellation Language files with the CS imaging software (Carestream Dental, Atlanta, GA) and was generated as a digital model for analysis.

\section{Superimposition and data acquisition}

The 3-dimensional analysis software (Geomagic Qualify 2013®, 3D-systems, Morrisville, NC) was used to superimpose the IOS images with the best-fit algorithm. The first region of interest (ROI-1) used to evaluate reproducibility was the bucco-lingual surfaces of the entire teeth above the gingival line in the IOS1 and IOS2 images (Fig. 2). The second ROI (ROI-2) comprised the occluso-buccal surfaces of the teeth above the upper-most margin of the bracket bases and the lingual surfaces of the teeth (Fig. 3). To assess the trueness of IOSb images, superimposed IOS1 and 2 images were cut according to ROI-2 and defined as IOSc images (IOS1c and IOS2c, respectively; Fig. 3). Differences between the IOS images were presented as average surface errors of the total arch, anterior, premolar, and molar regions in the maxillary and mandibular dentition.

\section{Statistical analysis}

Power analysis with $\alpha=0.05$, effect size $=0.90$, and power $(1-\beta)=0.80$ showed requirement of 13 surface error values (G* Power 3.1.9.7; Heinrich-Heine-University, Düsseldorf, Germany) [20]. Accordingly, more than 26 IOS images were needed because one average surface error was derived from a pair of IOS images.

When evaluating the accuracy of digital images, reproducibility is usually defined as the agreement among repeated data and trueness as closeness to the reference data $[9,18]$. To evaluate the reproducibility of IOS images as baseline, the average surface errors, the image differences obtained after superimpositions of IOS1 and IOS2, were determined via descriptive statistics and intraclass correlation coefficients (ICC). Conformity, how well the average surface errors among IOS1c, IOS2c, and IOSb images accurately correspond to each other, was analyzed by Lin's concordance correlation coefficients (CCC) and Bland-Altman analysis. In addition, the trueness of IOSb images was analyzed by comparing the average errors between IOSb and IOS1c and those between IOS1c and IOS2c using the Mann-Whitney $U$ test. To identify the difference between the average surface image errors of maxillary and mandibular arches, the Mann-Whitney $U$ test was used. The Kruskal-Wallis test was performed to evaluate surface errors among the anterior, premolar, and molar regions in both arches. All statistical data were analyzed with the SPSS software (Version 22.0, IBM, Armonk, NY).

\section{Results}

A total of 84 IOS images, consisted of 42 from maxillary and 42 from mandibular arches, was selected according to the inclusion criteria (Table 1, Fig. 1). According to the post hoc 
Fig. 1 Cohort diagram showing selection of intraoral scan images

Fig. 2 Study workflow of intraoral scan (IOS) images taking, their superimposition, and analysis using the Geomagic software program. To evaluate the reproducibility of IOS images, IOS1 and IOS2 images scanned twice at 2-week intervals, were superimposed, and average surface errors between them $[\Delta$ IOS $(1,2)]$ were measured based on the first region of interest (ROI-1), which were established as the bucco-lingual surfaces of the entire teeth above the gingival line
Intraoral scan (IOS) images from 140 patients, who underwent pre-orthodontic treatment records, were examined

Inclusion criteria:

Permanent dentition with fully erupted second molars,

No missing teeth,

No metal crowns,

Data scanned within one month, before and immediately after the orthodontic bracket bonding,

crowding less than or equals to $5 \mathrm{~mm}$

Total 84 IOS images (42 maxillary and 42

mandibular arch images) were included

from 14 consecutive patients 

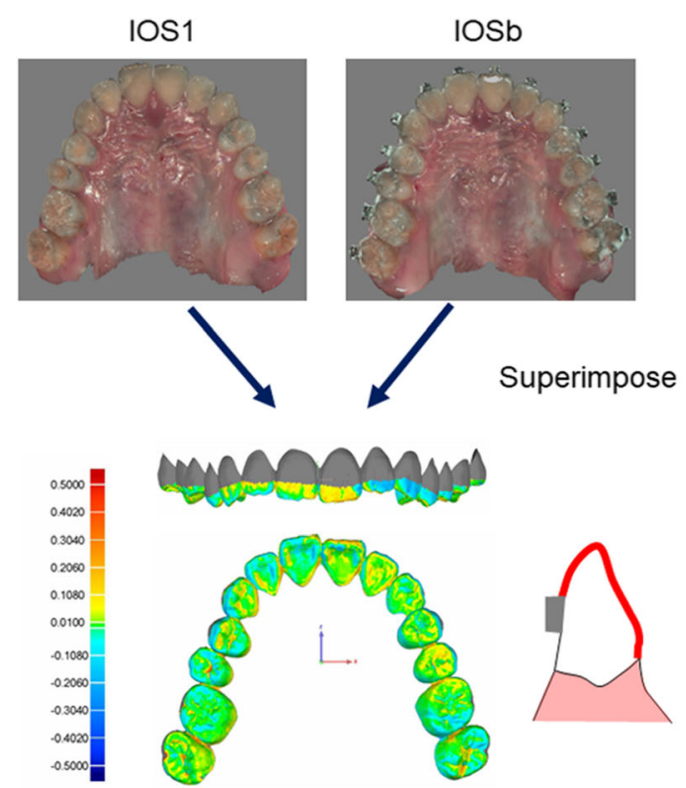

$\triangle \mathrm{IOS}(1 \mathrm{c}, \mathrm{b})$

Fig. 3 Study workflow of intraoral scan (IOS) images taking, their superimposition, and analysis using the Geomagic software program. To assess trueness of the IOS after bracket bonding (IOSb) images, IOS1 and IOSb images were superimposed, and average surface errors [ $\Delta$ IOS (1c, b)] were obtained based on the second ROI (ROI-2), which was the

power analyses with $\alpha$ (two-tailed $)=0.05$, effect size $=0.9$, and $n=14$, the estimated power $(1-\beta)$ of the study was 0.86 .

\section{Average surface errors $[\triangle \operatorname{IOS}(1,2)]$ and their reliability between repeated IOS images in maxillary and mandibular dentition}

As presented in Table 2, the average surface error in the total arch between the IOS1 and IOS2 images was $57 \pm 8 \mu \mathrm{m}$ in the maxillary dentition and $59 \pm 14 \mu \mathrm{m}$ in the mandibular dentition. There were no significant differences of the average errors among anterior, premolar, and molar regions in the maxillary and mandibular arches. In addition, intra-observer reliability of average surface errors was almost perfect in the total and anterior regions of IOS 1 and IOS 2 images $(0.911 \leq \mathrm{ICC} \leq$

Table 1 Characteristics of IOS1, IOS2, and IOSb images

\begin{tabular}{llll}
\hline & \multicolumn{2}{l}{ IOS images } & \\
\cline { 2 - 4 } Dentition & IOS1 & IOS2 & IOSb \\
\hline Maxilla $(n, 42)$ & 14 & 14 & 14 \\
Mandible $(n, 42)$ & 14 & 14 & 14 \\
\hline
\end{tabular}

IOS1 first intraoral scan as pre-orthodontic digital impression; IOS2 second intraoral scan before bracket bonding; IOSb IOS with orthodontic brackets after bonding

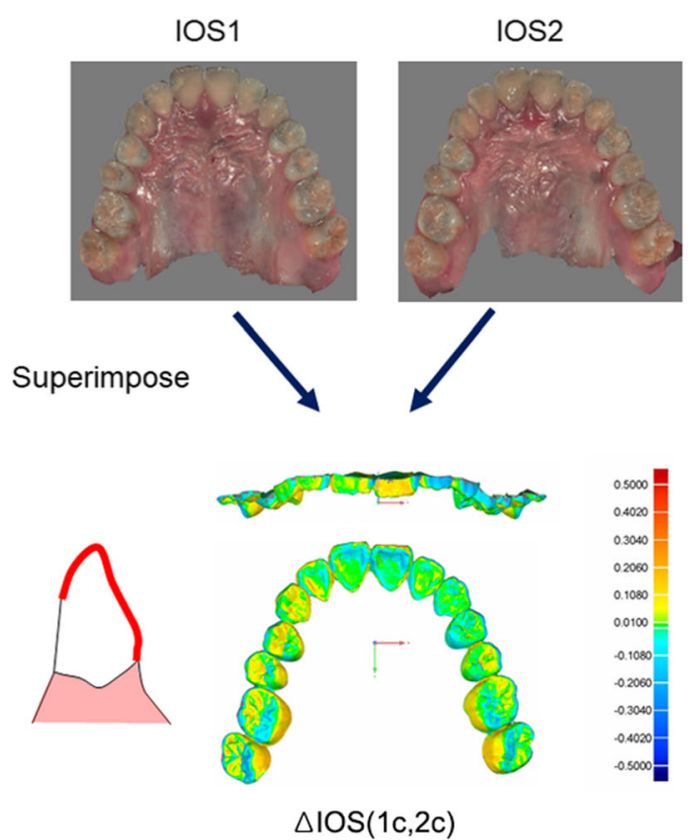

occluso-buccal surfaces of the teeth above the upper-most margin of the bracket bases and the lingual surfaces of the teeth. Also, the superimposed IOS1 and IOS2 images were cut according to ROI-2 and defined as IOSc images (IOS1c and IOS2c, respectively) for the comparison of the surface errors $[\Delta \operatorname{IOS}(1 \mathrm{c}, 2 \mathrm{c})]$

$0.991)$ and moderate in the maxillary premolar and molar regions $(0.435 \leq \mathrm{ICC} \leq 0.447)$.

\section{Reliability and conformity of average surface errors among IOS1C, IOS2c, and IOSb images in maxillary and mandibular dentition}

Intra-observer reliability of average surface errors was almost perfect between IOS1c and IOS2c [ $\Delta$ IOS $(1 \mathrm{c}, 2 \mathrm{c})]$ images $(0.989 \leq$ ICC $\leq 1.000$; Table 3$)$.

In conformity, all regions presented high values of CCC $(\geq 0.984)$ in the average surface errors between IOS1c and IOS2c images. However, the regions presented low to moderate values of $\mathrm{CCC}$ in the average surface errors between IOS1c (or 2c) and IOSb images [ $\Delta$ IOS $(1 \mathrm{c}, \mathrm{b})$ and $\Delta$ IOS $(2 \mathrm{c}, \mathrm{b})$; Table 3]. In addition, Bland-Altman plot showed larger deviations in $\Delta \operatorname{IOS}(1 \mathrm{c}, \mathrm{b})$ and $\Delta \operatorname{IOS}(2 \mathrm{c}, \mathrm{b}) \mathrm{com}$ pared to those of $\Delta$ IOS (1c, 2c) (Fig. 4).

\section{Average surface errors among IOS1c, IOS2c and IOSb images, and their comparisons in the maxillary/mandibular dentition}

As shown in Table 4, the average errors between IOSb and IOS1c images were significantly larger in the total, anterior, premolar, and molar regions in the maxillary arch compared to those between IOS1c and IOS2c images (all $P<0.001$ ). 
Table 2 Average surface errors and their reliability between repeated IOS images

\begin{tabular}{|c|c|c|c|c|c|c|c|c|c|}
\hline \multirow[t]{3}{*}{ Dentition } & \multirow[t]{3}{*}{ Region } & \multicolumn{8}{|c|}{ Average surface errors $[\Delta \operatorname{IOS}(1,2) ;$ unit, $\mu \mathrm{m}]$} \\
\hline & & \multirow[t]{2}{*}{ Mean } & \multirow[t]{2}{*}{ SD } & \multirow[t]{2}{*}{$\operatorname{Max}$} & \multirow[t]{2}{*}{ Min } & \multicolumn{2}{|c|}{$95 \% \mathrm{CI}$} & \multirow[t]{2}{*}{$P^{*}$} & \multirow[t]{2}{*}{$\mathrm{ICC}[95 \% \mathrm{CI}]$} \\
\hline & & & & & & Lower & Upper & & \\
\hline \multirow[t]{4}{*}{ Maxilla } & Total & 57 & 8 & 77 & 48 & 53 & 62 & $\mathrm{n} / \mathrm{a}$ & $0.991[0.934 / 0.999]$ \\
\hline & Anterior & 54 & 11 & 72 & 33 & 48 & 60 & 0.201 & $0.944[0.580 / 0.994]$ \\
\hline & Premolar & 54 & 12 & 71 & 18 & 47 & 61 & & $0.447[-1.715 / 0.936]$ \\
\hline & Molar & 63 & 13 & 86 & 46 & 56 & 71 & & $0.435[-4.091 / 0.941]$ \\
\hline \multirow[t]{4}{*}{ Mandible } & Total & 59 & 14 & 82 & 35 & 51 & 67 & $\mathrm{n} / \mathrm{a}$ & $0.907[0.290 / 0.990]$ \\
\hline & Anterior & 55 & 14 & 81 & 38 & 47 & 63 & 0.262 & $0.983[0.831 / 0.998]$ \\
\hline & Premolar & 48 & 11 & 70 & 31 & 42 & 54 & & $0.914[0.373 / 0.991]$ \\
\hline & Molar & 61 & 21 & 97 & 33 & 49 & 73 & & $0.911[-0.013 / 0.991]$ \\
\hline
\end{tabular}

$\triangle \operatorname{IOS}(1,2)$ the average surface errors, representing image difference obtained after superimposition and cutting of ISO1 and IOS2 images according to ROI-1; IOS1 first intraoral scan as pre-orthodontic digital impression; IOS2 second intraoral scan before bracket bonding; Total whole dentition; anterior, premolar, and molar regions were divided by contact points in the dentition after superimposition of the two images; Max maximum; Min minimum; $C I$ confidence interval

${ }^{*}$ Kruskal Wallis test; n/a; not applicable; ICC, intraclass correlation coefficients; ICC > 0.8/0.6/0.4/0.2 represent almost perfect, substantial, moderate, or mediocre reliability, respectively

Likewise, in the mandibular arch, the average errors between $\mathrm{IOSb}$ and IOS1c images exhibited significantly larger values in all regions (all, $P<0.001$ ). There were no significant differences of average errors among the regions (anterior, premolar, and molar) in either the maxillary or mandibular arch.

\section{Average surface errors of repeated IOSc or IOSb and IOS1c images between maxillary and mandibular arches}

Average surface errors of IOSb and IOS1c images showed larger values compared with those of repeated IOSc images, but not significantly different among the regions between the maxillary and mandibular arches (Table 5).

\section{Discussion}

With increasing needs for digital impressions, intraoral scanning for orthodontic treatment as well as diagnosis may be necessary under conditions of orthodontic appliances such as brackets. For this reason, the accuracy of IOS images on dental arches with orthodontic appliances needs to be evaluated. This study sought to compare the accuracy between IOS

Table 3 Reliability and conformity of the average surface errors among IOS1c, IOS2c, and IOSb images

\begin{tabular}{|c|c|c|c|c|c|}
\hline & & \multirow{2}{*}{$\begin{array}{l}\text { Reliability } \\
\text { ICC }[95 \% \mathrm{CI}] \\
\Delta \mathrm{IOS}(1 \mathrm{c}, 2 \mathrm{c})\end{array}$} & \multicolumn{3}{|l|}{ Conformity } \\
\hline & & & $\Delta \operatorname{IOS}(1 \mathrm{c}, \mathrm{b})$ & $\begin{array}{l}\text { CCC }[95 \% \mathrm{CI}] \\
\Delta \operatorname{IOS}(2 \mathrm{c}, \mathrm{b})\end{array}$ & $\Delta \operatorname{IOS}(1 \mathrm{c}, 2 \mathrm{c})$ \\
\hline \multirow[t]{4}{*}{ Maxilla } & Total & $1.000[0.997 / 1.000]$ & $0.013[-0.457 / 0.478]$ & $0.014[-0.458 / 0.479]$ & $0.999[0.994 / 1.000]$ \\
\hline & Anterior & $0.999[0.991 / 1.000]$ & $0.307[-0.662 / 0.892]$ & $0.331[-0.651 /-0.535]$ & $0.997[0.975 / 1.000]$ \\
\hline & Premolar & $0.999[0.996 / 1.000]$ & $-0.342[-0.882 / 0.586]$ & $-0.330[-0.877 / 0.591]$ & $0.999[0.990 / 1.000]$ \\
\hline & Molar & 0.995 [0.889/0.999] & $-0.033[-0.502 / 0.451]$ & $-0.045[-0.550 / 0.484]$ & 0.987 [0.948/0.997] \\
\hline \multirow[t]{4}{*}{ Mandible } & Total & 0.994 [0.878/0.999] & $-0.641[-0.894 /-0.076]$ & $-0.577[-0.867 / 0.004]$ & $0.984[0.923 / 0.997]$ \\
\hline & Anterior & $1.000[0.998 / 1.000]$ & $0.538[0.198 / 0.762]$ & $0.550[0.207 / 0.773]$ & $1.000[0.999 / 1.000]$ \\
\hline & Premolar & $1.000[1.000 / 1.000]$ & $0.600[-0.115 / 0.905]$ & $0.604[-0.102 / 0.906]$ & $1.000[0.999 / 1.000]$ \\
\hline & Molar & 0.989 [0.906/0.999] & $-0.476[-0.916 / 0.484]$ & $-0.607[-0.947 / 0.372]$ & $0.972[0.785 / 0.843]$ \\
\hline
\end{tabular}

$\Delta \operatorname{IOS}(1 c, 2 c)[$ or $\Delta \operatorname{IOS}(1 c, b)$, or $\Delta \operatorname{IOS}(2 c, b)]$ the average surface errors, representing image difference obtained after superimposition and cutting of the two IOS images according to ROI-2; ICC intraclass correlation coefficients; ICC > 0.8/0.6/0.4/0.2 represent almost perfect, substantial, moderate, or mediocre reliability, respectively; $C C C$ Lin's concordance correlation coefficients; $C C C$ of $>0.8 / 0.6 / 0.4 / 0.2$ or $\leq 0.2$ represent almost perfect, substantial, moderate, mediocre, or low conformity, respectively; $C I$ confidence interval 

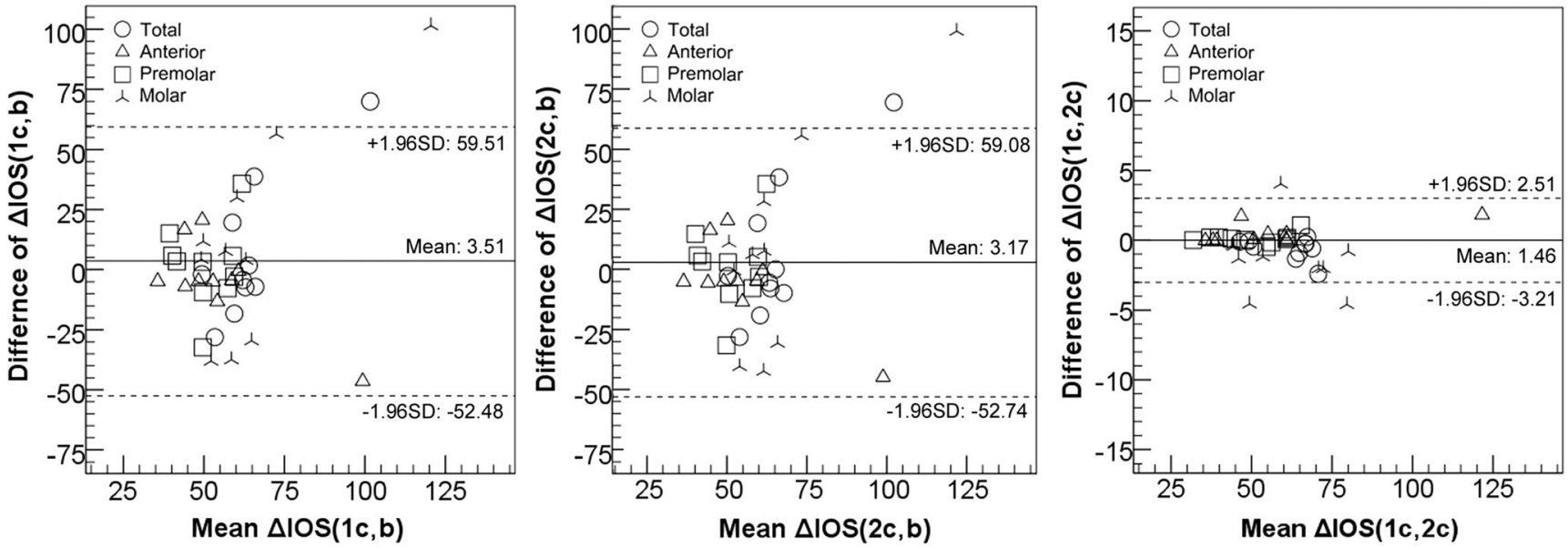

Fig. 4 Bland-Altman plot of average surface errors among IOS1c, IOS2c, and IOSb images

images obtained with and without brackets. As a baseline, we evaluated the reproducibility of IOS images acquired directly from both arches. The specific aim of the study was to evaluate the trueness of IOS images with orthodontic brackets.

Regarding the reproducibility of digital images in this study, the ICC of average surface errors between IOS1 and IOS2 images was almost perfect in the total regions, which implied that intraoral scanning was reliable (Table 2). Consistent with this result, Kirschneck et al. reported that intraoral scanning showed sufficient reliability and validity for clinical use, with higher deviations in intraoral scan images compared to extraoral scan of plaster models [21].

The difference of IOS1 and IOS2 images showed mean surface deviations ranging from $57 \mu \mathrm{m}$ to $59 \mu \mathrm{m}$ in the total arch of the maxillary and mandibular dentitions. A recent study on digital impressions using CS 3600 demonstrated a precision of $46 \mu \mathrm{m} \pm 5 \mu \mathrm{m}$, but they evaluated it on the maxillary plaster models [22]. A systemic review on the accuracy of scanning reported that the deviation values of the IOS image of the entire dentition by intraoral and laboratorial scanners were between $17 \mu \mathrm{m}$ and $378 \mu \mathrm{m}$ and suggested that intraoral scanning of complete dentition exhibited adequate accuracy [15]. In addition, Lim et al. reported a different range of deviation according to type of intraoral scanner, with the Trios showing greater precision (mean error, $52.3 \mu \mathrm{m}$ ) compared to iTero $(60.5 \mu \mathrm{m})$ in 10 repeated patient oral cavity scans [23]. Some studies found that image errors seemed to result from various factors such as type of scanner, performer's experience, existence of crowding, and scanning technique [23-26]. In our study, the surface error range of repeated IOS images is similar to or slightly larger than those of previous studies. This difference can be partially explained

Table 4 Average surface errors among IOS1c, IOS2c, and IOSb images and their comparisons in the maxillary/mandibular dentition

\begin{tabular}{|c|c|c|c|c|c|c|c|c|c|c|c|c|c|c|c|c|}
\hline \multirow[t]{3}{*}{ Dentition } & \multirow[t]{3}{*}{ Region } & \multicolumn{6}{|c|}{ Average surface errors $[\Delta \operatorname{IOS}(1 \mathrm{c}, 2 \mathrm{c}) ;$ unit, $\mu \mathrm{m})$} & \multirow{3}{*}{$P^{*}$} & \multicolumn{6}{|c|}{ Average surface errors $[\Delta \operatorname{IOS}(1 \mathrm{c}, \mathrm{b}) ;$ unit, $\mu \mathrm{m}]$} & \multirow{3}{*}{$P^{*}$} & \multirow{3}{*}{$P^{\dagger}$} \\
\hline & & \multirow[t]{2}{*}{ Mean } & \multirow[t]{2}{*}{$\mathrm{SD}$} & \multirow[t]{2}{*}{ Max } & \multirow[t]{2}{*}{ Min } & \multicolumn{2}{|c|}{$95 \% \mathrm{CI}$} & & \multirow[t]{2}{*}{ Mean } & \multirow[t]{2}{*}{$\mathrm{SD}$} & \multirow[t]{2}{*}{ Max } & \multirow[t]{2}{*}{ Min } & \multicolumn{2}{|c|}{$95 \% \mathrm{CI}$} & & \\
\hline & & & & & & Lower & Upper & & & & & & Lower & Upper & & \\
\hline \multirow[t]{4}{*}{ Maxilla } & Total & 55 & 10 & 69 & 40 & 49 & 60 & $\mathrm{n} / \mathrm{a}$ & 97 & 28 & 150 & 57 & 81 & 112 & $\mathrm{n} / \mathrm{a}$ & $<0.001$ \\
\hline & Anterior & 45 & 9 & 61 & 34 & 39 & 50 & 0.274 & 93 & 40 & 209 & 44 & 70 & 117 & 0.944 & $<0.001$ \\
\hline & Premolar & 47 & 9 & 66 & 37 & 42 & 53 & & 96 & 36 & 157 & 38 & 75 & 117 & & $<0.001$ \\
\hline & Molar & 53 & 14 & 77 & 38 & 45 & 61 & & 91 & 39 & 159 & 10 & 68 & 113 & & $<0.001$ \\
\hline \multirow[t]{4}{*}{ Mandible } & Total & 58 & 13 & 82 & 42 & 51 & 66 & $\mathrm{n} / \mathrm{a}$ & 95 & 29 & 159 & 53 & 78 & 112 & $\mathrm{n} / \mathrm{a}$ & $<0.001$ \\
\hline & Anterior & 54 & 24 & 122 & 36 & 40 & 68 & 0.310 & 94 & 27 & 132 & 32 & 78 & 109 & 0.805 & $<0.001$ \\
\hline & Premolar & 45 & 12 & 74 & 31 & 38 & 52 & & 101 & 63 & 294 & 35 & 65 & 138 & & $<0.001$ \\
\hline & Molar & 54 & 17 & 83 & 33 & 44 & 64 & & 95 & 27 & 144 & 59 & 79 & 110 & & $<0.001$ \\
\hline
\end{tabular}

$\Delta \operatorname{IOS}(1 c, 2 c)$ [or $\triangle \operatorname{IOS}(1 c, b)]$ the average surface errors, representing image difference obtained after superimposition and cutting of the two IOS images according to ROI-2; Max maximum; Min minimum; CI confidence interval

* Kruskal Wallis test

${ }^{\dagger}$ Mann Whitney $U$ test; $n / a$ not applicable 
Table 5 Average surface errors of IOS1c and 2c or IOSb and 1c images between maxillary and mandibular arches

\begin{tabular}{|c|c|c|c|c|c|c|c|c|c|c|}
\hline \multirow[t]{3}{*}{ Region } & \multicolumn{5}{|c|}{$\begin{array}{l}\text { Average surface errors }[\Delta \operatorname{IOS}(1 \mathrm{c}, 2 \mathrm{c}) ; \text { unit, } \\
\mu \mathrm{m}]\end{array}$} & \multicolumn{5}{|c|}{$\begin{array}{l}\text { Average surface errors }[\Delta \operatorname{IOS}(1 \mathrm{c}, \mathrm{b}) \text {; unit, } \\
\mu \mathrm{m}]\end{array}$} \\
\hline & \multicolumn{2}{|c|}{ Maxilla } & \multicolumn{2}{|c|}{ Mandible } & \multirow[t]{2}{*}{$P^{\prime}$} & \multicolumn{2}{|c|}{ Maxilla } & \multicolumn{2}{|c|}{ Mandible } & \multirow[t]{2}{*}{$P^{\prime}$} \\
\hline & Mean & $\mathrm{SD}$ & Mean & $\mathrm{SD}$ & & Mean & SD & Mean & SD & \\
\hline Total & 55 & 10 & 58 & 13 & 0.635 & 97 & 28 & 95 & 29 & 0.701 \\
\hline Anterior & 45 & 9 & 54 & 24 & 0.352 & 93 & 40 & 94 & 27 & 0.401 \\
\hline Premolar & 47 & 9 & 45 & 12 & 0.285 & 96 & 36 & 101 & 63 & 0.839 \\
\hline Molar & 53 & 14 & 54 & 17 & 0.946 & 91 & 39 & 95 & 27 & 0.874 \\
\hline
\end{tabular}

$\Delta \operatorname{IOS}(1 c, 2 c)$ [or $\triangle \operatorname{IOS}(1 c, b)]$ the average surface errors, representing image difference obtained after superimposition and cutting of the two IOS images according to ROI-2

${ }^{\dagger}$ Mann Whitney $U$ test due to the scanner types, which have different data acquisition methods and light sources [17]. It can also be attributed to in vivo scanning, which exhibited lower accuracy than ex vivo scanning due to its weakness such as patient movement, limited access in intraoral space, and saliva [27].

To evaluate the effect of orthodontic brackets on surface errors of acquired IOS images, we superimposed the IOSb and IOS1 images and the IOS1 and IOS2 images and cut them according to ROI-2 for comparison of surface errors. The ROI-2 was established as the lingual and occluso-buccal surfaces of teeth above the upper-most margin of the bracket bases for the following reasons: (1) the accuracy of these areas could be closely associated with fabrication of additional orthodontic appliances or printing surgical wafers; (2) the cervical surfaces of the teeth under the brackets may be affected by the residual bonding resin; (3) the technical difficulty of exact exclusion of the bracket area after superimposition.

Regarding the reliability and conformity of the average surface errors among IOS1c, IOS2c, and IOSb images, the surface errors between IOS1c and IOS2c images (without brackets) were reliable and almost identical. On the other hand, low to moderate concordance of the average surface errors between IOS1c (or 2c) and IOSb images (with brackets) indicates larger deviations compared to those between IOS1c and IOS2c images (Table 3 and Fig. 4).

The difference of IOSb and IOS1c images exhibited an increase in average surface errors of $97 \mu \mathrm{m}$ in the maxillary arch to $95 \mu \mathrm{m}$ in the mandibular arch. These deviations between IOSb and IOS1c images were significantly larger in each region as well as the entire dentition compared to those between IOS1c and IOS2c images (Table 4). This means that IOSb images have lower trueness compared to IOSc images, and suggests that orthodontic brackets may affect the accuracy of IOS images. Therefore, the null hypothesis was rejected. This increase of surface error may be attributed to the following reasons: (1) repeated scanning of the bracket area after bonding and (2) scattered reflection resulting from scanning of metal or ceramic brackets. Park et al. showed that a digital image with lingual brackets had less accuracy than that of buccal brackets due to the short interbracket distance and difficulty with scanning [28]. However, they measured 2dimensional inter-molar widths in ex-vivo scans of ideal dental models with brackets.

Regarding clinical application, a recent study on the precision of 3D-printed splint generated from dental models with different offsets reported that 100-200 $\mu \mathrm{m}$ clearance was required for adequate adaptation of the splints [29]. Another validation study of 3D-printed wafers for orthognathic surgery found clinically acceptable mean distance error of $400 \mu \mathrm{m}$ [1]. The surface errors of 95 to $97 \mu \mathrm{m}$ (max, 150 to $159 \mu \mathrm{m}$ ) after bracket bonding in this study imply that intraoral scanning can be used to fabricate removable orthodontic appliances. To the best of our knowledge, there has been no information on the maximum acceptable errors of IOS images to be accurate enough for clinical use, and further study is needed.

In relation to regional differences, there was no significant difference of mean errors among anterior, premolar, and molar regions of repeated IOS images in each arch (Table 2). Differences in the regional errors of IOS images between the maxillary and mandibular arches were not found, irrespective of orthodontic brackets (Table 5). Lim et al. reported that scan images between maxillary and mandibular arches presented no significant difference [23]. On the other hand, Flügge et al. demonstrated larger average deviation $(57 \mu \mathrm{m})$ in the maxilla compared to the mandible $(43 \mu \mathrm{m})$ in full arch scans [27]. They reported that image errors resulted from steep-angled maxillary anterior teeth and complex anatomical shape of the molar area. In addition, another in vitro study found over -/under-estimated errors in the anterior and posterior area according to various scanners [19], adopting single image- or video-based system [30]. The difference in our results might be attributed to the specific ROI-2 based on bracket base, and partially explained by video-based scan system, which reported to be less influenced by the region being scanned [23]. 
The limitations of this study could involve the small sample size of IOS images, use of different brackets, and restriction of ROI. Further studies are needed to evaluate the influence of the amount of crowding, materials, and size of brackets on the accuracy of IOS images in larger samples. Moreover, it may be necessary to examine whether the buccal and lingual positions of brackets will have different effects on the accuracy of IOS images.

\section{Conclusions}

The average surface errors of the scans with brackets showed increased values compared with those without brackets. This suggests that orthodontic brackets could affect the trueness of intraoral scan images.

\section{Compliance with ethical standards}

Conflict of interest The authors declare that they have no conflict of interest.

Ethical approval All procedures performed in studies involving human participants were reviewed and approved by the institutional review board and in accordance with the 1964 Helsinki Declaration and its later amendments or comparable ethical standards.

Informed consent For this type of retrospective, non-interventional clinical study, formal consent is not required.

Open Access This article is licensed under a Creative Commons Attribution 4.0 International License, which permits use, sharing, adaptation, distribution and reproduction in any medium or format, as long as you give appropriate credit to the original author(s) and the source, provide a link to the Creative Commons licence, and indicate if changes were made. The images or other third party material in this article are included in the article's Creative Commons licence, unless indicated otherwise in a credit line to the material. If material is not included in the article's Creative Commons licence and your intended use is not permitted by statutory regulation or exceeds the permitted use, you will need to obtain permission directly from the copyright holder. To view a copy of this licence, visit http://creativecommons.org/licenses/by/4.0/.

\section{References}

1. Shaheen E, Sun Y, Jacobs R, Politis C (2017) Three-dimensional printed final occlusal splint for orthognathic surgery: design and validation. Int J Oral Maxillofac Surg 46(1):67-71

2. Naidu D, Freer TJ (2013) Validity, reliability, and reproducibility of the iOC intraoral scanner: a comparison of tooth widths and Bolton ratios. Am J Orthod Dentofac Orthop 144(2):304-310

3. Rossini G, Parrini S, Castroflorio T, Deregibus A, Debernardi CL (2016) Diagnostic accuracy and measurement sensitivity of digital models for orthodontic purposes: a systematic review. Am J Orthod Dentofac Orthop 149(2):161-170

4. Lippold C, Kirschneck C, Schreiber K, Abukiress S, Tahvildari A, Moiseenko T, Danesh G (2015) Methodological accuracy of digital and manual model analysis in orthodontics-a retrospective clinical study. Comput Biol Med 62:103-109

5. Koretsi V, Tingelhoff L, Proff P, Kirschneck C (2018) Intraobserver reliability and agreement of manual and digital orthodontic model analysis. Eur J Orthod 40(1):52-57

6. Graf S, Vasudavan S, Wilmes B (2018) CAD-CAM design and 3dimensional printing of mini-implant retained orthodontic appliances. Am J Orthod Dentofac Orthop 154(6):877-882

7. Van der Meer WJ, Vissink A, Ren Y (2016) Full 3-dimensional digital workflow for multicomponent dental appliances: a proof of concept. J Am Dent Assoc 147(4):288-291

8. Grünheid T, McCarthy SD, Larson BE (2014) Clinical use of a direct chairside oral scanner: an assessment of accuracy, time, and patient acceptance. Am J Orthod Dentofac Orthop 146(5):673-682

9. Mangano F, Gandolfi A, Luongo G, Logozzo S (2017) Intraoral scanners in dentistry: a review of the current literature. BMC Oral Health 17(1):149

10. Mangano A, Beretta M, Luongo G, Mangano C, Mangano F (2018) Conventional vs digital impression: acceptability, treatment comfort and stress among young orthodontic patients. Open Dent J 12: $118-124$

11. Sfondrini MF, Gandini P, Malfatto M, Di Corato F, Trovati F, Scribante A (2018) Computerized casts for orthodontic purpose using powder-free intraoral scanners: accuracy, execution time, and patient feedback. Biomed Res Int 2018:4103232

12. Burhardt L, Livas C, Kerdijk W, van der Meer WJ, Ren Y (2016) Treatment comfort, time perception, and preference for conventional and digital impression techniques: a comparative study in young patients. Am J Orthod Dentofac Orthop 150(2):261-267

13. Aragón ML, Pontes LF, Bichara LM, Flores-Mir C, Normando D (2016) Validity and reliability of intraoral scanners compared to conventional gypsum models measurements: a systematic review. Eur J Orthod 38(4):429-434

14. Jacob HB, Wyatt GD, Buschang PH (2015) Reliability and validity of intraoral and extraoral scanners. Prog Orthod 16:38

15. Bohner L, Gamba DD, Hanisch M, Marcio BS, Tortamano Neto P, Laganá DC, Sesma N (2019) Accuracy of digital technologies for the scanning of facial, skeletal, and intraoral tissues: a systematic review. J Prosthet Dent 121(2):246-251

16. Jeong ID, Lee JJ, Jeon JH, Kim JH, Kim HY, Kim WC (2016) Accuracy of complete-arch model using an intraoral video scanner: an in vitro study. J Prosthet Dent 115(6):755-759

17. Kim RJ, Park JM, Shim JS (2018) Accuracy of 9 intraoral scanners for complete-arch image acquisition: a qualitative and quantitative evaluation. J Prosthet Dent 120(6):895-903.e1

18. Renne W, Ludlow M, Fryml J, Schurch Z, Mennito A, Kessler R, Lauer A (2017) Evaluation of the accuracy of 7 digital scanners: an in vitro analysis based on 3-dimensional comparisons. J Prosthet Dent 118(1):36-42

19. Treesh JC, Liacouras PC, Taft RM, Brooks DI, Raiciulescu S, Ellert DO, Grant GT, Ye L (2018) Complete-arch accuracy of intraoral scanners. J Prosthet Dent 120(3):382-388

20. Faul F, Erdfelder E, Buchner A, Lang A (2009) Statistical power analyses using $G^{*}$ Power 3.1: tests for correlation and regression analyses. Behav Res Methods 41(4):1149-1160

21. Kirschneck C, Kamuf B, Putsch C, Chhatwani S, Bizhang M, Danesh G (2018) Conformity, reliability and validity of digital dental models created by clinical intraoral scanning and extraoral plaster model digitization workflows. Comput Biol Med 100:114122

22. Mangano FG, Hauschild U, Veronesi G, Imburgia M, Mangano C, Admakin O (2019) Trueness and precision of 5 intraoral scanners in the impressions of single and multiple implants: a comparative in vitro study. BMC Oral Health 19(1):101 
23. Lim JH, Park JM, Kim M, Heo SJ, Myung JY (2018) Comparison of digital intraoral scanner reproducibility and image trueness considering repetitive experience. J Prosthet Dent 119(2):225-232

24. Anh JW, Park JM, Chun YS, Kim M, Kim M (2016) A comparison of the precision of three-dimensional images acquired by 2 digital intraoral scanners: effects of tooth irregularity and scanning direction. Korean J Orthod 46(1):3-12

25. Müller P, Ender A, Joda T, Katsoulis J (2016) Impact of digital intraoral scan strategies on the impression accuracy using the TRIOS pod scanner. Quintessence Int 47(4):343-349

26. Favero R, Volpato A, Francesco M, Fiore AD, Guazzo R, Favero L (2019) Accuracy of 3D digital modeling of dental arches. Dental Press J Orthod 24(1):38e1-38e7

27. Flügge TV, Schlager S, Nelson K, Nahles S, Metzger MC (2013) Precision of intraoral digital dental impressions with iTero and extraoral digitization with the iTero and a model scanner. Am J Orthod Dentofac Orthop 144(3):471-478

28. Park JM, Choi SA, Myung JY, Chun YS, Kim M (2016) Impact of orthodontic brackets on the intraoral scan data accuracy. Biomed Res Int 2016:5075182

29. Ye N, Wu T, Dong T, Yuan L, Fang B, Xia L (2019) Precision of 3D-printed splints with different dental model offsets. Am J Orthod Dentofac Orthop 155(5):733-738

30. Ender A, Mehl A (2015) In-vitro evaluation of the accuracy of conventional and digital methods of obtaining full-arch dental impressions. Quintessence Int 46(1):9-17

Publisher's note Springer Nature remains neutral with regard to jurisdictional claims in published maps and institutional affiliations. 